\title{
Investigation of Behaviour of Titanium Diboride Reinforced Boron Carbide-Silicon Carbide Composites against Cs-137 Gamma Radioisotope Source by Using Gamma Transmission Technique
}

\begin{abstract}
B. BuyuK ${ }^{a}$, A.B. Tugrul ${ }^{a}$, A.C. AkArsu ${ }^{b}$ And A.O. Addemir ${ }^{b}$
${ }^{a}$ ITU Energy Institute - Nuclear Research Division, Ayazaga Campus 34669, Maslak/Istanbul, Turkey ${ }^{b}$ ITU Metalurgical and Materials Engineering Faculty, Ayazaga Campus 34669, Maslak/Istanbul, Turkey

Boron carbide is a material which has wide application areas in industry including nuclear technology. Titanium diboride reinforced boron carbide-silicon carbide composites were studied for searching of the behaviour against the gamma ray. It has been adopted that depending on their properties such improved materials can be used in nuclear technology. For the investigation of the gamma radiation behaviour of these materials, Cs-137 radioisotope was used as gamma source in the experiments which have a single gamma-peak at $0.662 \mathrm{MeV}$. Gamma transmission technique was used for the measurements. Different reinforcing ratios, titanium diboride reinforced boron carbide-silicon carbide composites were evaluated in relation to gamma transmission and the results of the experiments were interpreted and compared with each other. It could be understood that the increasing ratio of titanium diboride in boron carbide-silicon carbide composites causes higher hardness, strength and linear attenuation coefficient values but decrease the mass attenuation coefficient.
\end{abstract}

PACS: 25.20.Dc

\section{Introduction}

Boron carbide is a material that is used in wide application areas in industry. Some of these areas are the nuclear technology, military industry, ceramic industry and air-space industry $[1,2]$. Boron carbide has low-density, high hardness and corrosion resistance, chemical stability and high neutron capture feature [2]. Some boron carbide application fields are lightweight ceramic armor, sand blasting nozzles, nuclear reactors, reactor control rods and the radiation shielding materials $[2,3]$. However, boron carbide is brittle, has low strength and high temperature sintering properties $[3,4]$. Since the sintering of pure boron carbide to high densities is difficult, specific additives such as $\mathrm{SiC}, \mathrm{Al}_{2} \mathrm{O}_{3}, \mathrm{TiB}_{2}, \mathrm{AlF}_{3}, \mathrm{~W}_{2} \mathrm{~B}_{5}$, elemental boron and carbon have been used as sintering aids to increase the sintered density $[2-5]$.

In this study, titanium diboride reinforced with boron carbide-silicon carbide composites were studied for searching of the behaviour against the gamma ray. For the investigation of the gamma radiation behaviour of these materials, Cs-137 radioisotope was used as gamma source in the experiments which has a single gamma-peak at $0.662 \mathrm{MeV}$ and half life is $30.1 \mathrm{y}[6,7]$.

Gamma transmission technique was used for the measurements. Experimental geometry and experimental setup were prepared carefully and scattering effect was minimized. In the experiments, PM1401K model, scintillation detector and multi-channel analyzer, was used for the measurement of the gamma peak. All the measurements were implemented by taking at least three counts in the same geometry.

Different reinforcing ratios, titanium diboride reinforced with boron carbide-silicon carbide composites, were evaluated in relation to gamma transmission and the results of the experiments were interpreted and compared with each other. Therefore, the behavior of titanium diboride reinforced boron carbide-silicon carbide composites were investigated against Cs-137 gamma radioisotope source by using gamma transmission technique.

\section{Experiments and materials}

Gamma transmission technique is based on penetrating gamma rays through materials. Detector and gamma source were put on both sides of the material within the same axis. Then gamma radiation counts are measured reaching the detector from the source are measured. The counts with material and without material are compared and evaluate $[6-8]$. Figure 1 shows schematic view of gamma transmission technique.

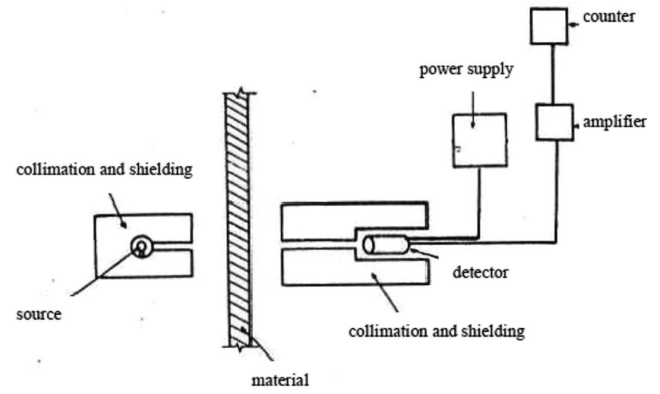

Fig. 1. Schematic view of gamma transmission technique.

The radiation passing through the material is calculated by the following equation:

$$
I=I_{0} \mathrm{e}^{-\mu x},
$$

where $I$ and $I_{0}$ are the transmitted and initial gamma ray 
intensities, respectively, $\mu$ is linear attenuation coefficient of material at specific $\gamma$-ray and $x$ is the thickness of the material.

The materials which were used in the experiments have different titanium diboride ratios in the composites. Thus they are coded according to their titanium diboride ratios by volume in composites. Table I shows the materials used in the experiments and their ratios by volume in the composite materials and also their hardness, strength and density properties [5].

All composite materials were sintered at $2250{ }^{\circ} \mathrm{C}$ for $2 \mathrm{~h}$ under $130 \mathrm{MPa}$ pressure. The materials which were used in the experiments have about $1 \times 0.5 \times 2 \mathrm{~cm}^{3}$ dimensions. Cs-137 gamma radiation source which has $8.9 \mu \mathrm{Ci}$ was used in the experiments. Lead blocks were used for radiation shielding and collimation. The collimator diameter is $7 \mathrm{~mm}$. The distance between the detector and source is $10 \mathrm{~cm}$. Firstly, the background radiation was measured. Then Cs-137 gamma source was set. Initial intensity count $\left(I_{0}\right)$ was measured. Then materials were set and intensity counts $(I)$ were measured for all thickness values. All counts were measured three times for $600 \mathrm{~s}$ and net counts calculated by reducing background value. Average values and standard deviations were calculated. For rational evaluating, relative intensity $\left(I / I_{0}\right)$ values were calculated. Results were given with tables. Relative intensity-material thickness graph was drawn for each titanium diboride ratio. Exponential distribution was shown on graphs and exponential equations were calculated. Then results were evaluated and discussed.

\section{Experimental results}

Results for titanium diboride free boron carbidesilicon carbide composites, $2 \%$ (by volume) titanium diboride reinforced boron carbide-silicon carbide composites and 4\% (by volume) titanium diboride reinforced boron carbide-silicon carbide composites are given in Table II.
Using the values in the tables relative intensitymaterial thickness graphs were drawn for all titanium diboride ratios. Exponential fitted equations were calculated. Figure 2 shows all titanium diboride reinforced boron carbide-silicon carbide composites comparatively.

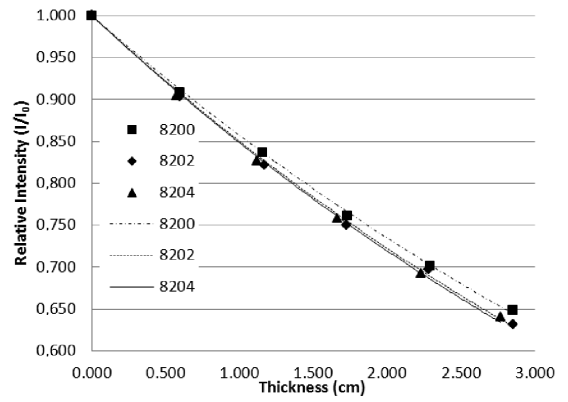

Fig. 2. Relative intensity for titanium diboride reinforced boron carbide-silicon carbide composites.

\section{Discussion and conclusion}

The linear attenuation coefficients $(\mu)$ of all materials were calculated by using Fig. 2. The correlation coefficients of results are $R^{2}=0.999$ and 0.998 and 0.998 , respectively. The mass attenuation coefficients $\left(\mu_{\mathrm{m}}=\mu / \rho\right)$ of the materials were also calculated. Finally, the mass attenuation coefficients of the composites were compared with the theoretical values which were calculated from XCOM computer code [9].

Table III shows the linear and mass attenuation coefficients for the composite materials and \% difference of experimental and theoretical mass attenuation coefficient values of the studied materials. It could be said that theoretical and experimental mass attenuation coefficients are of same tendency and close to each other. The difference percentage is about $6-8 \%$.

\section{TABLE I}

The contents and the properties of the composite materials which were used in the experiments [5].

\begin{tabular}{c|c|c|c|c|c|c}
\hline \hline $\begin{array}{c}\text { Material } \\
\text { (code) }\end{array}$ & $\begin{array}{c}\mathrm{B}_{4} \mathrm{C} \\
{[\% \text { volume] }}\end{array}$ & $\begin{array}{c}\mathrm{SiC} \\
{[\% \text { volume] }}\end{array}$ & $\begin{array}{c}\mathrm{TiB}_{2} \\
{[\% \text { volume }]}\end{array}$ & $\begin{array}{c}\text { Hardness } \\
\text { [Vickers] }\end{array}$ & $\begin{array}{c}\text { Strength } \\
{[\mathrm{MPa}]}\end{array}$ & $\begin{array}{c}\text { Density } \\
{\left[\mathrm{g} / \mathrm{cm}^{3}\right]}\end{array}$ \\
\hline 8200 & 80 & 20 & 0 & $1777.6 \pm 93.22$ & $218.925 \pm 29.14$ & 2.244 \\
8202 & 78.4 & 19.6 & 2 & $1902.57 \pm 131.8$ & $261.425 \pm 25.60$ & 2.361 \\
8204 & 76.8 & 19.2 & 4 & $1983.67 \pm 56.78$ & $276.125 \pm 78.79$ & 2.429
\end{tabular}

TABLE III

The linear and mass attenuation coefficients of 8200, 8202 and 8204 composite materials.

\begin{tabular}{c|c|c|c|c}
\hline \hline \multirow{2}{*}{$\begin{array}{c}\text { Material } \\
\text { (code) }\end{array}$} & Linear attenuation & \multicolumn{3}{|c}{ Mass attenuation coefficient $\left[10^{-2} \mathrm{~cm}^{2} / \mathrm{g}\right]$} \\
\cline { 3 - 5 } & coefficient $\left[\mathrm{cm}^{-1}\right]$ & Experimental & $\mathrm{XCOM}$ & $\%$ Difference \\
\hline 8200 & 0.154 & 6.863 & 7.359 & 6.744 \\
8202 & 0.162 & 6.862 & 7.355 & 6.710 \\
8204 & 0.165 & 6.793 & 7.352 & 7.605
\end{tabular}


TABLE II

Results for titanium diboride reinforced and without reinforced boron carbide-silicon carbide composites with Cs-137 gamma source.

\begin{tabular}{c|c|c|c|c|c|c|c}
\hline \hline Materials & \multicolumn{3}{|c}{} & \multicolumn{3}{c}{ Accumulation time =600 s } \\
\cline { 2 - 7 } & $\begin{array}{c}\text { Thickness } \\
{[\mathrm{cm}]}\end{array}$ & $\begin{array}{c}\text { Net } \\
\text { count 1 }\end{array}$ & $\begin{array}{c}\text { Net } \\
\text { count 2 }\end{array}$ & $\begin{array}{c}\text { Net } \\
\text { count } 3\end{array}$ & $\begin{array}{c}\text { Average } \\
\text { count }\end{array}$ & $\begin{array}{c}\text { Standard } \\
\text { deviation }\end{array}$ & $\begin{array}{c}\text { Relative } \\
\text { count }\end{array}$ \\
\hline \multirow{2}{*}{8200} & 0 & 8047 & 8132 & 8056 & 8079 & 47 & 1.000 \\
& 0.598 & 7325 & 7361 & 7330 & 7339 & 19 & 0.908 \\
& 1.156 & 6723 & 6754 & 6791 & 6756 & 34 & 0.836 \\
& 1.729 & 6111 & 6153 & 6185 & 6150 & 37 & 0.761 \\
& 2.291 & 5649 & 5689 & 5663 & 5667 & 20 & 0.701 \\
& 2.855 & 5267 & 5215 & 5235 & 5239 & 26 & 0.648 \\
\hline 8202 & 0.000 & 8135 & 8128 & 8211 & 8158 & 46 & 1.000 \\
& 0.594 & 7372 & 7393 & 7320 & 7362 & 38 & 0.902 \\
& 1.169 & 6654 & 6652 & 6780 & 6695 & 73 & 0.821 \\
& 1.724 & 6147 & 6121 & 6073 & 6114 & 37 & 0.749 \\
& 2.283 & 5736 & 5689 & 5621 & 5682 & 58 & 0.696 \\
& 2.853 & 5116 & 5196 & 5119 & 5144 & 45 & 0.631 \\
\hline 8204 & 0 & 8135 & 8128 & 8116 & 8127 & 10 & 1.000 \\
& 0.571 & 7346 & 7297 & 7367 & 7337 & 36 & 0.903 \\
& 1.119 & 6718 & 6696 & 6725 & 6713 & 15 & 0.826 \\
& 1.664 & 6163 & 6121 & 6171 & 6152 & 27 & 0.757 \\
& 2.229 & 5610 & 5656 & 5590 & 5619 & 34 & 0.691 \\
& 2.769 & 5209 & 5198 & 5192 & 5200 & 8 & 0.640
\end{tabular}

It could be understood that the increasing ratio of titanium diboride in boron carbide-silicon carbide composites causes higher hardness, strength and linear attenuation coefficient values but decreases the mass attenuation coefficient. The mass attenuation coefficients are close to theoretical values. On the other hand, the production techniques of composite materials are very important. As a result, it was concluded that increase of the ratio of titanium diboride in the boron carbide-silicon carbide composites causes increase of gamma attenuation of the composites. Therefore, titanium diboride reinforced boron carbide-silicon carbide composites can be used in nuclear technology as a shielding material because of their improved hardness, strength and linear attenuation coefficient values.

\section{Acknowledgments}

The authors wish to thank BMBT Co. to their support about production of materials.

\section{References}

[1] S. Aktop, M.Sc. Thesis, ITU Institute of Science and Technology, Istanbul 2010.

[2] F. Thevenot, J. Europ. Ceram. Soc. 6, 205 (1990).

[3] N. Cho, Ph.D. Thesis, Georgia Institute of Technology, 2006.

[4] E. Turan, M.Sc. Thesis, ITU Institute of Science and Technology, Istanbul 2004.

[5] A.C. Akarsu, M.Sc. Thesis, ITU Institute of Science and Technology, Istanbul 2009.

[6] R. Halmshaw, Non-Destructive Testing, E. Arnold, London 1991.

[7] B. Büyük, A.B. Tuğrul, in: Xth National Nuclear Science and Technologies Congress, Vol. 1, p. 49, Mugla 2009.

[8] G. Földiak, Industrial Application of Radioisotopes, Elsevier, Amsterdam 1986.

[9] M.J. Berger, J.H. Hubbell, S.M. Seltzer, J. Chang, J.S. Coursey, R. Sukumar, D.S. Zucker, K. Olsen, XCOM: photon cross-section database. http://www.nist.gov/pml/data/xcom/index.cfm , U.S. 